\title{
Remission of Insulin Autoimmune Syndrome in a Patient with Graves' Disease by Treatment with Methimazole
}

\author{
Reiko Okabe, Masaaki Inaba, Masayuki Hosol, Eiji Ishimura, Yasuro Kumeda, \\ Yoshiki Nishizawa and Hirotoshi MorII
}

\begin{abstract}
The patient, a 24-year-old man, had suffered from hunger, sweating, tachycardia and palpitation for three years. He was diagnosed as having Graves' disease (GD) and treated with methimazole (MMI) for 3 months. He noted that palpitation and perspiration seemed to particularly occur when he was hungry, and thus he was examined to determine whether these symptoms were caused by hypoglycemia. As a markedly elevated immunoreactive insulin level and the presence of insulin antibody in serum were found, he was diagnosed as having insulin autoimmune syndrome (IAS). HLA typing revealed the patient to be positive for group Bw62/Cw4/DR4, which is reportedly a specific HLA type in MMI-treated euthyoroid GD patients with IAS. In spite of the continuation of MMI treatment, the \% binding of IRI decreased and the hypoglycemic episode disappeared. In contrast to the previously reported MMI induced IAS in GD cases, MMI is unlikely to have exacrebated IAS in the present case, although his HLA combination is identical to that of the previous cases.

(Internal Medicine 38: 482-485, 1999)
\end{abstract}

Key words: Graves'disease (GD), methimazole (MMI), human lymphocyte antigen (HLA) typing

\section{Introduction}

The first case of spontaneous hypoglycemia without prior history of exogenous insulin administration was reported by Hirata et al in 1972 (1). Insulin autoimmune syndrome (IAS), which consists of the combination of a high level of total serum immunoreactive insulin (IRI), the presence of insulin antibody (IA), and fasting hypoglycemia, is reportedly the third leading cause of hypoglycemia in Japan (2). The first case of IAS associated with Graves' disease (GD) was first reported in 1974 (3). Burch et al (4) recently proposed administration of methimazole (MMI) as a risk factor in the development of IAS in GD patients. A genetic predisposition may be important in the pathogenesis of IAS, as reflected by an apparent human lymphocyte antigen (HLA) association in the limited number of cases of IAS. According to the report by Uchigata et al, all 13 MMI-treated GD patients later diagnosed as having IAS had HLA-Bw62/Cw4/DR4, whereas only 1 of 50 GD patients who had not developed IAS had the combination of HLABw62/Cw4/DR4 (5).

We report here an interesting case of IAS in association with GD who had developed hypoglycemic episode already in the hyperthyroid state. He had HLA-Bw62/Cw4/DR4. MMI decreased the IA titer in parallel with the antibody titers against thyroid peroxidase (TPO) and thyroglobulin (Tg) as the patient's thyroid function was restored to normal level.

\section{Case Report}

A 24-year-old man, presented with finger tremor, palpitation, and perspiration for 3 years since 1994, was referred to Osaka City University Hospital in 1997 . The patient was 180.4 $\mathrm{cm}$ tall and weighed $62.0 \mathrm{~kg}$. Blood pressure was $134 / 58 \mathrm{mmHg}$, pulse rate $94 / \mathrm{m}$ regular, and temperature $36.2{ }^{\circ} \mathrm{C}$. A rubbery firm diffuse goiter was palpated. Proptosis measured by Hertel exophthalmometer was $25 \mathrm{~mm}$ on the right and $24 \mathrm{~mm}$ on the left. There was no abnormality in the thorax, chest, or abdomen. The complete blood count, urinalysis and blood chemistry on admission yielded normal values (Table 1). Thyroid function tests showed abnormally high levels of free $\mathrm{T}_{3}\left(\mathrm{fT}_{3}\right)$ and free $\mathrm{T}_{4}\left(\mathrm{fT}_{4}\right)\left(\mathrm{fT}_{3}: 18.3 \mathrm{pg} / \mathrm{ml}, \mathrm{fT}_{4}: 8.5 \mathrm{ng} / \mathrm{dl}\right)$ with thyroid stimulating hormone (TSH) level below the nomal detection limit. Together with an increased radioiodine uptake (50.3\%), he was diagnosed as having GD. Probably due to his poor drug com-

From the Second Department of Internal Medicine, Osaka City Medical School, Osaka

Received for publication August 31, 1998; Accepted for publication December 22, 1998

Reprint requests should be addressed to Dr. Hiroyuki Yamashita, the First Department of Internal Medicine, Kyushu University, 3-1-1 Maidashi, Higashi-ku, Fukuoka 814-0133 
pliance, MMI at a daily dose of $30 \mathrm{mg}$ failed to normalize his thyroid function within 3 months (Table 2). He often complained that cold sweating with palpitations occurred particularly when he was hungry and that those symptoms improved after a meal. His plasma glucose level was disclosed to be 42 $\mathrm{mg} / \mathrm{dl}$ when he felt the above symptoms, raising the possibility of hypoglycemic episode. Fasting IRI was $81 \mu / \mathrm{ml}$, well above the upper normal limit, with \% binding of IRI as high as $70.3 \%$. He has a positive IA titer. An abdominal computerized tomography and ultrasound examination disclosed no mass lesion in the pancreas and negative fasting tests also negated the possibility of insulinoma.

As his serum $\mathrm{fT}_{3}$ and $\mathrm{fT}_{4}$ levels were reduced with the continuation of MMI treatment, a decrease of his \% binding of IRI occurred from $70.3 \%$ to $34.0 \% 2$ months after the reduction of serum thyroid hormone levels (Fig. 1), which was followed by the reduction in $\mathrm{Ab}$ titers for $\mathrm{Tg}$ and $\mathrm{TPO}$ (Fig. 2).

\section{Discussion}

The present case was presented with hyperthyroidism and hypoglycemic episode. Since he showed positive IA antibody together with high levels of fasting insulin and \% insulin binding he was suggested as having IAS. As his IA titer decreased by the treatment with MMI daily for 2 months, his hypoglycemic episode disappeared.

It is well recognized that GD is often accompanied by autoimmune diseases such as IAS. In such a case, since the hyperthyroid state masks the hypoglycemic episode by impairing glucose tolerance, IAS-induced hypoglycemic symptoms usually occur after the thyroid function was normalized by MMI treatment. Thus far, since MMI is hypothesized to cause IAS by generating insulin antigenicity through cleavage of the disulfide bonds of the insulin molecules by its SH residue $(6,7)$, it is not until the introduction of treatment with MMI that GD patients develop IAS without prior evidence of insulin injection. However, methimazole, in vitro, did not have any effect on insulin structure or its immunoreactivity even at a substantially higher concentration than those obtained by the usual therapeutic doses. Therefore, it seems unlikely that SH drugs act directly on the insulin molecule in vivo. Alternatively, MMI (8) and other SH drugs (9) may augment immune responses and lead to IAS in certain predisposed patients, such as those with GD having a certain HLA type. Uchigata et al (5) reported that all 13 MMI-treated GD patients who had subsequent development of IAS had HLA-Bw62/Cw4/DR4, whereas 4 of 11 IAS patients without GD who had been taking drugs containing a $\mathrm{SH}$ residue, had HLA-Bw62/Cw4/DR4. On the other hand, only 1 of 50 GD patients who did not develop IAS had the combination of HLA-Bw62/Cw4/DR4. This study showed that the combination of HLA-Bw62/Cw4/DR4 may be essential for the development of IAS in GD patients taking drugs containing the $\mathrm{SH}$ residue. The fact that the present patient's HLA typing was disclosed to be Bw62/Cw4/DR4 supports this hypothesis.

Interestingly, the present case developed a hypoglycemic
Table 1. Laboratory Findings on Admission

\begin{tabular}{ll}
\hline Hematology & \\
White blood cell & $5,300 / \mu \mathrm{l}$ \\
Red blood cell & $544 \times 10^{4} / \mu \mathrm{l}$ \\
Hemoglobin & $16.0 \mathrm{~g} / \mathrm{dl}$ \\
Hematocrit & $47.7 \%$ \\
Platelets & $26 \times 10^{4} / \mu \mathrm{l}$ \\
Biochemistry & \\
Total protein & $7.1 \mathrm{~g} / \mathrm{dl}$ \\
Albumin & $4.0 \mathrm{~g} / \mathrm{dl}$ \\
Na & $142 \mathrm{mEq} / l$ \\
K & $4.0 \mathrm{mEq} / l$ \\
Cl & $104 \mathrm{mEq} / l$ \\
Blood urea nitrogen & $14 \mathrm{mg} / \mathrm{dl}$ \\
Creatinine & $0.6 \mathrm{mg} / \mathrm{dl}$ \\
Aspartate aminotransferase & $32 \mathrm{IU} / l$ \\
Alanine aminotransferase & $53 \mathrm{IU} / l$ \\
Total bilirubin & $0.8 \mathrm{mg} / \mathrm{dl}$ \\
Urinalysis & \\
Protein & $(-)$ \\
Glucose & $(-)$ \\
Sediments & \\
Red blood cell & $1 / 10 \mathrm{HPF}$ \\
White blood cell & $15 / 1 \mathrm{HPF}$ \\
\hline
\end{tabular}

Table 2. Endocrinological Data on Admission

\begin{tabular}{lll}
\hline & Levels & Normal range \\
\hline $\mathrm{fT}_{3}$ & 14.3 & $(2.6-4.3 \mathrm{pg} / \mathrm{ml})$ \\
$\mathrm{fT}_{4}$ & 4.4 & $(0.9-1.7 \mathrm{ng} / \mathrm{dl})$ \\
$\mathrm{TSH}$ & 0.012 & $(0.4-4.0 \mu \mathrm{IU} / \mathrm{ml})$ \\
$\mathrm{MCHA}$ & $\times 25,600$ & $(<100)$ \\
$\mathrm{TGHA}$ & $<100$ & $(<100)$ \\
$\mathrm{TR}-\mathrm{Ab}$ & 11.1 & $(<10 \%)$ \\
$\mathrm{Tg}-\mathrm{Ab}$ & 3.3 & $(0-0.4 \mathrm{U} / \mathrm{ml})$ \\
$\mathrm{TPO}-\mathrm{Ab}$ & 86.3 & $(0-0.3 \mathrm{U} / \mathrm{ml})$ \\
FPG & 81 & $(70-105 \mathrm{mg} / \mathrm{dl})$ \\
$\mathrm{HbA}$ & 5.1 & $(4.0-5.5 \%)$ \\
$\mathrm{CPR}$ & 4.8 & $(1.5-3.5 \mathrm{ng} / \mathrm{ml})$ \\
IRI & 81 & $(2.4-23.2 \mu \mathrm{U} / \mathrm{ml})$ \\
$\%$ IRI binding & 70.3 & $(0-10 \%)$ \\
Radioiodine uptake & 50.3 & \\
\hline
\end{tabular}

$\mathrm{fT}_{3}$ : free triiodothyronine, $\mathrm{fT}_{4}$ : free thyroxine, $\mathrm{TSH}$ : thyroid stimulating hormone, MCHA: microsome test, TGHA: thyroid test, TR-Ab: antibodies for $\mathrm{TSH}$ receptor, $\mathrm{Tg}-\mathrm{Ab}$ : antibodies for thyroglobulin, TPO-Ab: antibodies for thyroid peroxidase, FPG: fasting plasma glucose, $\mathrm{HbA}_{1 \mathrm{C}}$ : hemoglobin $\mathrm{A}_{1 \mathrm{C}}$, CPR: C-peptide immunoreactivity, IRI: immunoreactive insulin.

episode even in the hyperthyroid state, helping us to diagnose that his IAS may have occurred as early as 3 months after the introduction of MMI treatment. The hypoglycemic episode disappeared as his thyroid function was normalized by the continuation of MMI treatment. Graves' immunoglobulin G (IgG) 


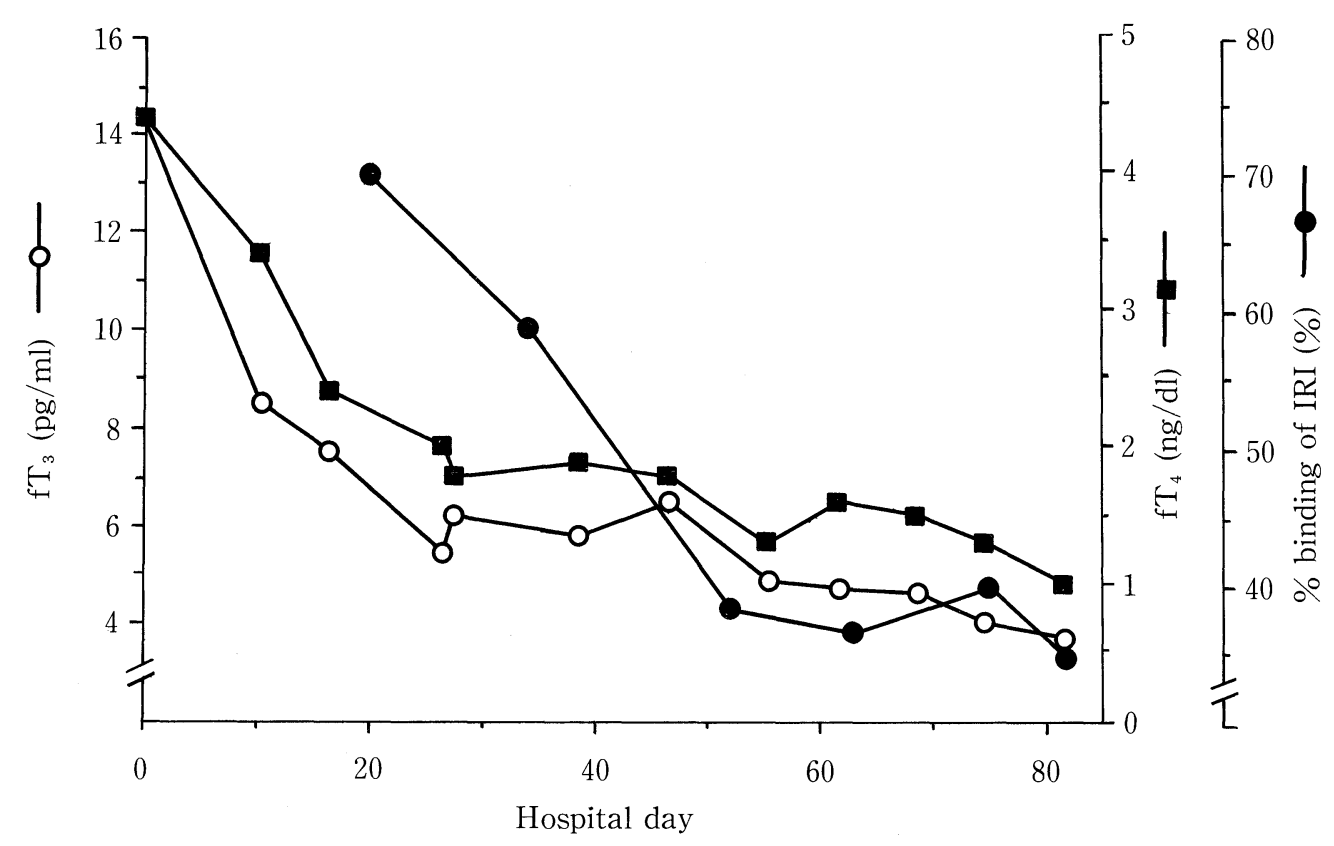

Figure 1. Changes in serum levels of $\mathrm{fT}_{3}$ and $\mathrm{fT}_{4}$ and $\%$ binding of IRI during treatment with MMI.

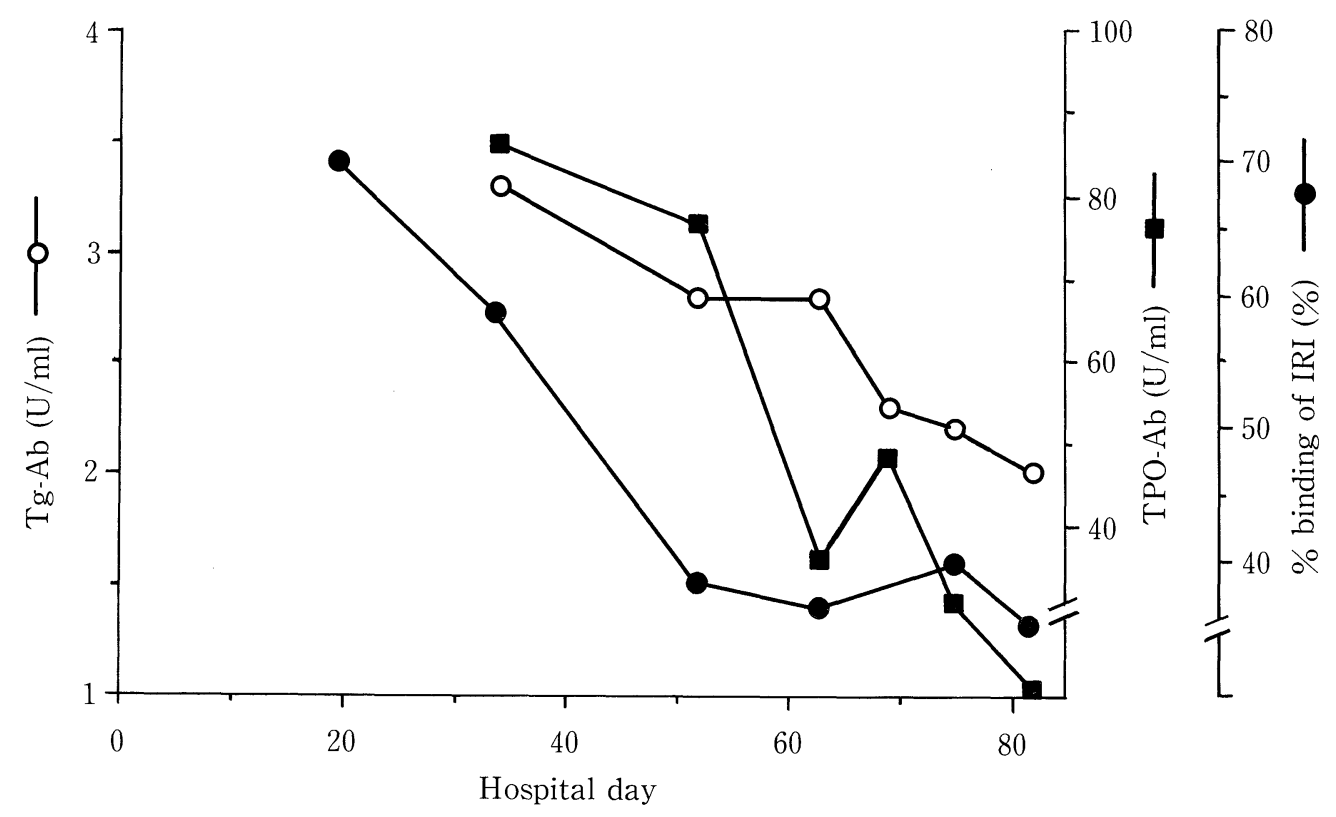

Figure 2. Changes in antibody titers for TPO and TG along with that of \% binding of IRI during treatment with MMI.

is known to propagate thyroid-specific autoaggression by continued induction of DR antigens. Since MMI is known to rapidly reduce Graves' IgG-induced DR expression possibly by reducing Graves' IgG (10), it is reasonable to speculate that MMI treatment decreased the IA titer by attenuating Graves' IgG-induced DR expression. Since our case showed a marginal increase in TR-Ab, although not evident, TR-Ab was reduced from $11.1 \%$ to $4.0 \%$ during MMI treatment for 2 months. Furthermore, MMI decreased the IA titer along with those for TPO$\mathrm{Ab}$ and $\mathrm{Tg}-\mathrm{Ab}$. The time course of reduction in TR-Ab seems very similar to that of TPO-Ab (data not shown).

Since hyperthyroidism is known to induce the hyperimmune 


\section{Remission of IAS in a GD Patient by MMI}

state, it is possible that the normalization of thyroid function may restore the hyperimmune response observed in the hyperthyroid state to the normal level. Recently, lines of evidence have accumulated to suggest interleukin-6 (IL-6) as a factor inducing hyperimmune state in GD, as reflected by the positive correlation of serum $\mathrm{fT}_{3} / \mathrm{fT}_{4}$ levels and the absolute numbers of circulating T cell and B cells bound to IL-6 (11). It seems unlikely that MMI contributed to the exacerbation of IAS at least in this case, because of the decrease in IA titer in spite of the continuation of MMI treatment. Evidence has been accumulated to indicate that MMI has an immunomodulatory effect. Immunization with a human monoclonal anti-DNA antibody (16/6 Id) induces systemic lupus erythematosus (SLE)like syndrome in mice, in which MHC class 1 antigens play a critical role, as demonstrated by the finding that MHC class 1deficient mice are resistant to disease induction. MMI, which has been shown to repress major histocompatibility complex (MHC) class 1 transcription in some cell lines, prevents the development of clinical manifestations of SLE in 16/6Id-immunized mice (12), probably by reducing class 1 expression on peripheral blood lymphocytes aslo in vivo. MMI is also effective in mitigating the development of SLE-like autoimmune disease in (NZB X NZW) F1 mice (13). Furthermore, MMI strongly protected against the development of ocular disease, such as blepharitis in BALB/c mice (14). These reports suggested that MMI may be useful in the clinical treatment of SLE and other autoimmune disease such as IAS by repressing MHC class 1 .

In summary, we treated a rare case who presented a hypoglycemic episode even in the hyperthyroid state. Since his hypoglycemia was accounted for by the generation of IA, it disappeared as his \% binding of IRI decreased with the normalization of thyroid function by MMI treatment. Therefore, it was unlikely that MMI exacrebated IAS in our case as all the previously reported GD cases, although his HLA combination is Bw62/Cw4/DR4 as in the previous cases.

\section{References}

1) Hirata $\mathrm{Y}$, Ishizu $\mathrm{H}$. Elevated insulin-binding capacity of serum proteins in a case with spontaneous hypoglycemia and mild diabetes not treated with insulin. Tohoku J Exp Med 107: 277-286, 1972.

2) Takayama-Hasumi S, Eguchi Y, Sato A, Morita C, Hirata Y. Insulin autoimmune syndrome is the third leading cause of spontaneous hypoglycemic attacks in Japan. Diabetes Res Clin Prac 10, 211-214, 1990.

3) Hirata Y, Tominaga M, Ito JI, Noguchi A. Spontaneous hypoglycemia with insulin autoimmunity in Graves' disease. Ann Intern Med 81: 214 218, 1974.

4) Bruch HB, Clement S, Sokol MS, Landry F. Reactive hypoglycemic coma due to insulin autoimmune syndrome: case report and literature review. Am J Med 92: 681-685, 1992 (see comments).

5) Uchigata $Y$, Kuwata $S$, Tsushima T, et al. Patients with Graves' disease who developed insulin autoimmune syndrome (Hirata Disease) Possess HLA-Bw62/Cw4/DR4 carrying DRB1*0406. J Clin Endocrinol Metab 77: 249-254, 1993.

6) Antoniades HN, Huber AM, Boshell BR, Saravis CA, Gershof SN. Studies on the state of insulin in blood: properties of circulating "free" and "bound" insulin. Endocrinology 76: 709-721, 1965.

7) Ichihara K, Shima K, Saito Y, Nonaka K, Tarui S. Mechanism of hypoglycemia observed in a patient with insulin autoimmune syndrome. Diabetes 26: 500-506, 1977.

8) Okabe N, Inoue K, Mori R. Effects of antithyroid drugs on lymphocyte prosiferative responses to lectins: relationship between insulin autoimmune syndrome and methimazole. J Clin Lab Immunol 11: 167-171, 1983.

9) Mori H, Nagai H, Koda A. Effect of alpha-mercaptopropionylglycine (alpha-MPG) and sodium dipropylacetate (DPA) on antibody formation (III) (author's transl). Nippon Yakurigaku Zasshi 74: 797-804, 1978.

10) Bodolay E, Suranyi P, Juhasz F, Stenszky V, Balazs C, Farid NR. Methimazole blocks Graves' IgG but not interferon-gamma HLA-DR expression by thyroid cells. Immunol Lett 18: 167-171, 1988.

11) Corrales JJ, Orfao A, Lopez A, Mories MT, Miralles JM, Ciudad J. Analysis of IL-2 and IL-6 Binding to Peripheral Blood Lymphocytes in Graves' Disease: Relationship with Disease Activity. Cytometry 30: 118-123, 1997.

12) Singer DS, Kohn LD, Zinger H, Mozes E. Methimazole prevents induction of experimental systemic lupus erythematosus in mice. J Immunol 153: 873-880, 1994.

13) Mozes E, Zinger H, Kohn LD, Singer DS. Spontaneous autoimmune disease in (NZBÑNZW)F1 mice is ameliorated by treatment with methimazole. J Clin Immunol 18: 106-113, 1998.

14) Chan CC, Gery I, Kohn LD, Nussenblatt RB, Mozes E, Singer DS. Periocular inflammation in mice with experimental systemic lupus erythematosus. A new experimental blepharitis and its modulation. J Immnol 154: 4830-4835, 1995. 